\section{論 久}

Original Paper

\section{キルン燒成法による焼却炉飛灰中 各種金属の揮発分離技術*}

\title{
Analysis of Reaction and Mechanism in Heavy Metal Volatilization of Incinerator Fly Ash Roasting
}

by Mototsugu MATSUNO ${ }^{\mathrm{a} *}$, Katsuhiro TOMODA ${ }^{\mathrm{a}}$, and Takashi NAKAMURA ${ }^{\mathrm{b}}$

a. Sumitomo Metal Mining,Co., Ltd., 5-11-3, Sinbashi, Minato-ku, Tokyo, 105-8716, Japan (*Corresponding author: E-mail mototsugu_matsuno@ni.smm.co.jp)

b. Institute of Multidisciplinary Research for Advanced Materials, Tohoku University (IMRAM)

A novel detoxification process for incinerator fly ash was proposed, and the removal mechanism of heavy metals from the fly ash was investigated. The process comprises of roasting the fly-ash extrudates with a rotary kiln, and removes heavy metals by chloridizing volatilization, giving harmless resultant extrudates which contain immobilized heavy metals at trace concentration. The developed roasting technique was unique, as it utilized chlorine originally contained in the fly ash and did not need additional chlorine source. Our detailed investigation proved that appropriate control of bed layer in the kiln could keep reductive atmosphere that should enhance volatilization of metals at either chloride or metals form.

The extrudates derived from the process, compared to conventional chelate-solidified ash or to melting solid matter, showed less metals elution at leachate test, as well as contained descended metals content which satisfied the soil environmental standards revised recently.

KEY WORDS : Incinerator Fly Ash, Chlolide Volatilization, Recycle, Roasting

\section{1.は じめに}

焼却炉飛扊は重金属類を含むことから特別管理廃棄物に指定さ れ処分に際して無害化が義務付けられている。我国では特に重金 属類を徹底的に除去しかつ溶出を防止した無害化技術が強く望ま れており，技術開発とともにメカニズムの理論解析及びその具体 的実証が必要である。更にリサイクルの観点からも, 残さ成分そ のものを有効活用できる飛灰処理技術が強く望まれている。

本開発技術はロータリーキルンを用いた高温焼成法であり，重 金属類は塩化物や金属形態で揮発分離される 1-10,12,13)。また本開 発技術は従来の無害化技術とは異なり，重金属を低レベルまで除 去する技術を含むものであり，残存量，溶出量ともに新土壌污染 対策法の污染土壤評価基準值を充分満足するものである。

本開発技術は焼却炉飛死類に含有される塩成分を利用した塩化 揮発法であるとともに，同時に飛灰類に含有される炭素成分を利 用した還元揮発法でもある。その目的は有害重金属類の高度分離 除去であり，鉄鋼業における副産物，リサイクル物等のいわゆる 二次鉄源から重金属を除去し，鉄鋼二次原料製造を目的とする塩 化揮発法 ${ }^{9)}$ とは，目的も技術も異なるものである。

本報告は有害物である飛灰類の新しい技術に関するメカニズム 解析とその具体的実証結果について報告する。

* 2003 年 12 月 11 日受付 2004 年 7 月 6 日受理

1. 住友金属鉱山(株) 技術本部 知的財産部部長 兼 エネルギー・環境事業部

2. 住友金属鉱山（株）エネルギー・環境事業部 事業室課長

3. 工博 東北大学教授 多元物質科学研究所

[ 著者連絡先 ] FAX 03-3436-7738 (住友金属鉱山 (株) ・松野) E-mail : mototsugu_matsuno@ni.smm.co.jp

キーワード : 焼却炉飛灰，塩化物揮発，リサイクル，焼成法
なお最も問題とされる成分である鉛に関しては既に報告した ${ }^{14)}$ 今回はその他問題成分であるカドミウム $(\mathrm{Cd})$, クロム $(\mathrm{Cr})$ の他, 有価金属である Zn 等に関し, 実証試験結果を用いて, 除去メカニ ズム及び除去条件などについて $\mathrm{Pb}$ と比較しつつ確認し考察する。 特に低温度において $\mathrm{Pb}$ の塩化揮発を実現するには塩化水素分圧を 高める必要があるが, $\mathrm{SO}_{2}$ ガスの関与があれば塩素源の添加がな くても可能性がある。しかしながら $\mathrm{Zn}$ の場合は $\mathrm{Pb}$ の場合よりさ らに高い塩化水素分圧を必要とするため, 比較的低温度領域で塩 化揮発を期待するよりも, 比較的高温度領域の還元揮発を期待す るほうが実用的であることが推察される。なおダイオキシン類 (DXNs) に関しては焼成ペレット, 排ガスとも充分低く別途報告し た $6,8-10)$ とおり問題はなかった。

\section{2. 試験設備及び試験方法}

大型キルン実証試験に先立ち, 静置式試験装置 ${ }^{1,17)}$ による基礎試 験も行い, 各重金属の残留量および溶出量の予備調査を実施した。

また Fig.1 には本新技術の大型キルンを使用した実証試験処理 フローを示した。実証試験キルン寸法は $0.9 \mathrm{~m} \phi \times 12 \mathrm{ml}$, 設計回転 数は $1 \sim 6 \mathrm{rpm}$, 設計処理能力は $100 \mathrm{~kg} / \mathrm{h}$ である。

大型キルンによる実証試験は, Fig.1 のように, まず焼却飛灰に コークス等の添加剤を加え, ミキサーで混合, 振動ミルで粉砕し た後, 水を加え押出成形して直径 $10 \mathrm{~mm} \times$ 長さ $5 \sim 15 \mathrm{~mm}$ の柱状 ペレットを得る。乾燥後, ロータリーキルンに投入, $1000^{\circ} \mathrm{C}$ 以上 で焼成した。試験ごとの焼成温度は各組成で安定処理が可能な最 高温度近傍で実施した。なお塩化物反応に必要な塩素源は特に添 加せず，また還元剤であるコークスも炭素濃度約 $5 \mathrm{mass} \%$ を目標 


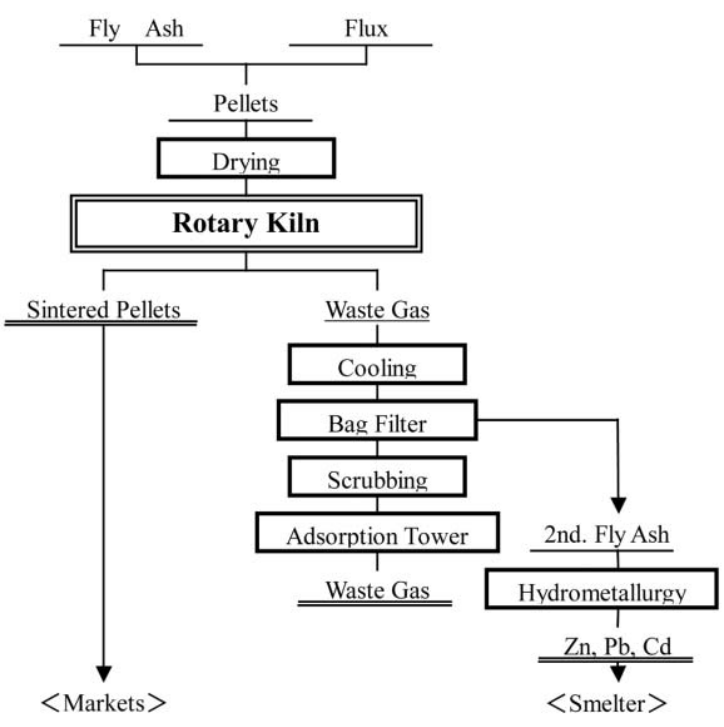

Fig. 1 Flow sheet of the fly ash treatment process.

Table 1 Typical chemical compositions of the fly ash used in the tests (Unit : mass\%).

\begin{tabular}{|c|c|c|c|c|c|c|c|c|c|c|c|c|}
\hline Type of fly ash & $\mathrm{SiO}_{2}$ & $\mathrm{Al}_{2} \mathrm{O}_{3}$ & $\mathrm{Fe}_{2} \mathrm{O}_{3}$ & $\mathrm{CaO}$ & $\mathrm{MgO}$ & $\mathrm{Na}_{2} \mathrm{O}$ & $\mathrm{K}_{2} \mathrm{O}$ & $\mathrm{ZnO}$ & $\mathrm{PbO}$ & $\mathrm{SO}_{3}$ & $\mathrm{Cl}$ & $\mathrm{C}$ \\
\hline $\mathrm{A}(\mathrm{EP}$ ash $)$ & 10.2 & 5.8 & 1.3 & 15.8 & \begin{tabular}{|l|}
2.9 \\
\end{tabular} & \begin{tabular}{|l|}
12.7 \\
\end{tabular} & 12.0 & 1.3 & 0.2 & 10.8 & 23.8 & 0.8 \\
\hline $\mathrm{B}$ (Ca ash) & 1.3 & 3.5 & 0.8 & 39.6 & 4.3 & 3.9 & 4.0 & 0.3 & 0.1 & 3.7 & \begin{tabular}{|l|}
13.3 \\
\end{tabular} & $\overline{1.9}$ \\
\hline C(EP ash) & 20.2 & \begin{tabular}{|l|}
13.0 \\
\end{tabular} & 1.5 & 17.0 & 3.2 & 9.1 & 8.5 & 2.4 & 0.8 & 4.8 & 13.0 & 2.4 \\
\hline
\end{tabular}

Table 2 The volatilization behavior of the various heavy metals (Basic test).

\begin{tabular}{|c|c|c|c|c|c|c|c|c|c|c|c|}
\hline & & \multicolumn{5}{|c|}{ Residual percent in the sintered pellet $(\%)$} & \multicolumn{5}{|c|}{ Elution $(\mathrm{mg} / \mathrm{L})^{(* 1)}$} \\
\hline \multicolumn{2}{|c|}{ Element } & $\mathrm{Pb}$ & $\mathrm{Zn}$ & $\mathrm{Cd}$ & $\mathrm{Cr}$ & $\mathrm{S}$ & $\mathrm{Pb}$ & $\mathrm{Zn}$ & $\mathrm{Cd}$ & $\mathrm{Cr}$ & $\mathrm{Cl}$ \\
\hline \multicolumn{2}{|c|}{ Before roasting } & 0.48 & 3.38 & 0.01 & 0.02 & 1.99 & - & - & - & - & - \\
\hline \multirow{8}{*}{ 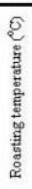 } & \multirow{2}{*}{950} & $\langle 0.01$ & 0.75 & $\langle 0.01$ & 0.02 & 1.53 & $\langle 0.01$ & 580 & 0.03 & $\langle 0.01$ & 6600 \\
\hline & & $\langle 0.01$ & 0.69 & $\langle 0.01$ & 0.02 & 1.54 & - & - & - & - & - \\
\hline & \multirow{2}{*}{1000} & $\langle 0.01$ & 0.07 & $\langle 0.01$ & 0.02 & 1.63 & $\langle 0.01$ & $\langle 0.5$ & $\langle 0.01$ & 0.01 & 200 \\
\hline & & $\langle 0.01$ & 0.07 & $\langle 0.01$ & 0.02 & 1.64 & - & - & - & - & - \\
\hline & \multirow{2}{*}{1050} & $\langle 0.01$ & 0.04 & $\langle 0.01$ & 0.02 & - & $\langle 0.01$ & 34 & 1.4 & 0.57 & 4700 \\
\hline & & $\langle 0.01$ & 0.03 & $\langle 0.01$ & 0.02 & - & - & - & - & - & - \\
\hline & \multirow{2}{*}{1100} & $\langle 0.01$ & 0.01 & $\langle 0.01$ & 0.02 & 0.87 & 0.01 & $\langle 0.5$ & 0.01 & 0.01 & 1.7 \\
\hline & & $\langle 0.01$ & 0.01 & $\langle 0.01$ & 0.02 & 0.93 & - & - & - & - & - \\
\hline
\end{tabular}

(*1)Measuring method of elution : Notification No.46 of Japan

に必要量添加調合した。排ガスは水噴霧により $200^{\circ} \mathrm{C}$ 以下まで急 冷し, 二次飛灰はバグフィルターで回収した。排ガス中には塩化 水素 $(\mathrm{HCl})$ ガス等が含まれることからスクラバーを使用し，活性 炭吸着装置を通して大気放出した。なおべッド層内ガス分析用サ ンプルは，瞬時キルンを停止し，シェルに設けたノズルからサン プリングパイプをベッド層中間部に装入し吸引して採取した。

Table 1 には一連の本試験に使用した代表的飛死組成例を示し た。試験では本技術が広範囲な組成で処理が可能であることを確 認するため, これら組成の大きく異なる各種飛灰類を使用した。

\section{3. 試 験 結 果}

\section{$3 \cdot 1$ 各重金属の揮発と溶出の概要}

Table 2 に基礎試験 ( 装置 ${ }^{17}$ ) における各重金属等の残留濃度, 溶出濃度等に関し，焼成温度の影響について調査した試験結果を 総括的に示した。試験試料は鉛，亜鉛の高い飛灰を使用した。 $\mathrm{Pb}$ は $950^{\circ} \mathrm{C}$ の高温度では充分揮発除去が期待でき, $\mathrm{Zn}$ もさらに温度 を高く寸ることで揮発が可能であることがわかる。また特に Zn の 溶出量が不規則な結果を示しており, 残留量と無関係な動きをす ることが推察される。

\section{$3 \cdot 2$ キルン内温度推移と各成分の挙動}

これまでの基礎試験における知見 $\left(\right.$ 装置 ${ }^{1,17)}$ ) などを確認し，か

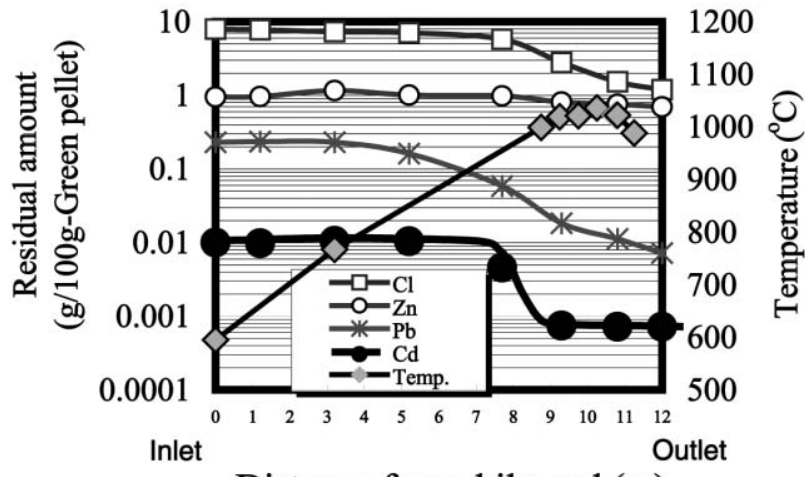

Distance from kiln end (m)

Fig. 2 Amounts of $\mathrm{Cd}, \mathrm{Zn}, \mathrm{Pb}$ and $\mathrm{Cl}$ remaining in pellets within rotary kiln.

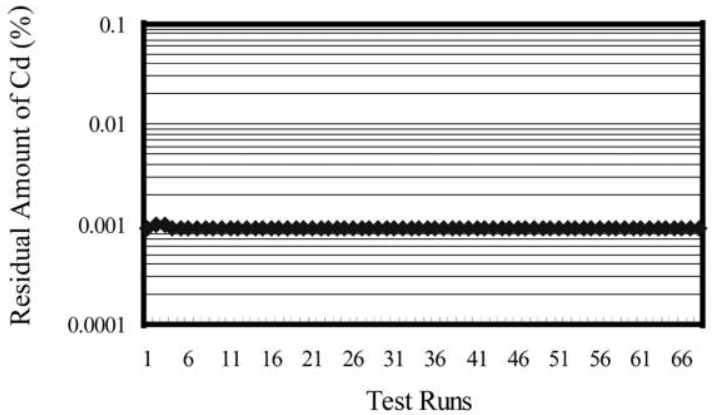

Fig. 3 Residual $\mathrm{Cd}$ in the roasted pellet

つ大型キルンにおける各成分の実際的な挙動を調査した。Fig.2 に 装入から排出にいたるペレット内各成分のキルン内挙動を一覧し て示した。これらより本実証試験条件では $\mathrm{Pb}, \mathrm{Zn}, \mathrm{Cd}$ ともそれ ぞれ特有な減少曲線を示しており, 揮発形態や揮発条件が金属に より異なる可能性がある事が推察される。

$\mathrm{Pb}$ は比較的低温領域から徐々に減少し始め, $900 \sim 950^{\circ} \mathrm{C}$ 付近 から急激な減少に転じ, 更に昇温や時間の経過に伴い徐々に減少 している。更に塩素 $(\mathrm{Cl})$ の減少挙動と定性的に類似しており, こ れら成分との関係が推察される。

一方 $\mathrm{Cd}$ は約 $900^{\circ} \mathrm{C}$ から急激な減少が起こり, かつ約 $1000^{\circ} \mathrm{C}$ 付 近で減少はほぼ終了している点が特徴である。減少曲線も比較的 単一で，塩素など他成分との類似性も見られない。

これに対し, Zn は $30 \%$ 程度しか揮発しておらず, また約 $950^{\circ} \mathrm{C}$ 付近で顕著に減少が現れていることから, 明らかに高温部のみで 起こっている点が特徴である。

\section{$3 \cdot 3$ 焼成ペレット中 $\mathrm{Cd}, \mathrm{Zn}$ 残留量}

Fig.3 に実証試験における焼成ペレット内 $\mathrm{Cd}$ 残留量を示した。 試験条件は, 組成 $\left(\mathrm{SiO}_{2}, \mathrm{Al}_{2} \mathrm{O}_{3}, \mathrm{CaO}, \mathrm{Na}_{2} \mathrm{O}\right)$, 装入量 $(70 \sim 300 \mathrm{~kg}$ $/ \mathrm{h})$, 回転数 $(1.5 \sim 2.5 \mathrm{rpm})$, 飛灰比率 $(20 \sim 80 \%)$ 他について設定 を変えて実施した。なお今回の実証試験では $\mathrm{Fe}$ は $\mathrm{Fe}_{2} \mathrm{O}_{3}$ 換算 $6 \%$, C は $5 \%$ に一定とし，焼成温度は組成に応じて対応，また酸素濃 度は排ガス中濃度 $2 \%$ 程度で実施した。Fig.3 に示されるように試 験条件を変えても $\mathrm{Cd}$ の残留量への影響は見られず，いずれの試 験データも新土壌污染防止法評価基準 $(\mathrm{Cd} \leqq 0.015 \%)$ などと比較 して充分低い結果となった。なお図中, $\mathrm{Cd}$ 分析值の $0.001 \%$ 未満 は目盛 $0.0009 \%$ にプロットした。

また, Zn に関しては今回の大型キルン実証試験では充分な還元 条件を与えなかったため揮発はあまり促進されなかった。

\section{$3 \cdot 4$ キルン内ガス分析結果}

Table 3 に実証試験キルン内ガス分析結果を示した。この結果か らべッド層内では酸素濃度も低く, $900{ }^{\circ} \mathrm{C}$ 付近では $\mathrm{Zn}$ に対しては 
Table 3 The $\mathrm{CO}, \mathrm{CO}_{2}$ and $\mathrm{O}_{2}$ concentrations measured in the bed layer of the kiln.

\begin{tabular}{c|c|c|c}
\hline $\begin{array}{c}\text { Sampling Point } \\
\text { (Temp.) }\end{array}$ & $\begin{array}{c}\text { No.6 } \\
\left(650{ }^{\circ} \mathrm{C}\right)\end{array}$ & $\begin{array}{c}\text { No.3 } \\
\left(900{ }^{\circ} \mathrm{C}\right)\end{array}$ & $\begin{array}{c}\text { No.2 } \\
\left(1000{ }^{\circ} \mathrm{C}\right)\end{array}$ \\
\hline $\mathrm{CO} \%$ & 0.97 & 6.5 & 54 \\
\hline $\mathrm{CO}_{2}$ & $\% 4$ & 514 & 17 \\
\hline $\mathrm{O}_{2} \%$ & $<0.1$ & $<0.1$ & $<0.1$ \\
\hline $\mathrm{CO}_{2} / \mathrm{CO}$ & 55 & 2.1 & 0.31 \\
\hline
\end{tabular}

Table 4 The $\mathrm{HCl}, \mathrm{SO}_{2}$ and $\mathrm{O}_{2}$ gas concentrations measured in the test kiln.

\begin{tabular}{l|ccc|ccc|ccc}
\hline $\begin{array}{l}\text { Sampling } \\
\text { Point (Temp.) }\end{array}$ & \multicolumn{3}{|c|}{$\begin{array}{c}\text { No.6 } \\
\left(650^{\circ} \mathrm{C}\right)\end{array}$} & \multicolumn{3}{c|}{$\begin{array}{c}\text { No.3 } \\
\left(900{ }^{\circ} \mathrm{C}\right)\end{array}$} & \multicolumn{3}{c}{$\begin{array}{c}\text { No.2 } \\
\left(1000{ }^{\circ} \mathrm{C}\right)\end{array}$} \\
\hline Gas & $\mathrm{SO}_{2}$ & $\mathrm{HCl}$ & $\mathrm{O}_{2}$ & $\mathrm{SO}_{2}$ & $\mathrm{HCl}$ & $\mathrm{O}_{2}$ & $\mathrm{SO}_{2}$ & $\mathrm{HCl}$ & $\mathrm{O}_{2}$ \\
\hline Gas Layer (\%) & 0.22 & 0.044 & 0.4 & 5.0 & 0.13 & 1.8 & 0.41 & 0.059 & $<1$ \\
Bed Laver (\%) & 0.0035 & 0.0012 & $<0.1$ & 1.2 & 0.015 & $<0.1$ & 0.061 & 0.005 & $<0.1$ \\
\hline
\end{tabular}

おおむね還元雾囲気は得られている。また $1000^{\circ} \mathrm{C}$ 付近では後述の Fig.12 に示すように金属状亜鉛安定領域を示し，処理条件の調整 により酸化亜鉛 $(\mathrm{ZnO})$ の還元が進む可能性もうかがえる。

また Table 4 にはキルン内ガス層およびベッド層の $\mathrm{HCl}$ ガス濃 度等の測定值を示した。全体的に比較的低い測定值を示した。

\section{4. 考察}

\section{$4 \cdot 1$ カドミウム $(\mathrm{Cd})$ の揮発形態}

$\mathrm{Cd}$ の挙動に関しては他の成分との関係が見られず (Fig.2), かつ 一定温度領域で速やかに低濃度まで減少しその後は安定してい る $^{4,6,8-10,13,14)}$ 。これは揮発除去機構が $\mathrm{Pb}$ と異なることを示唆し ていると考えられる。

$\mathrm{Cd}$ は焼成キルン装入時は $\mathrm{Pb}, \mathrm{Zn}$ と同様酸化物で供給される。 また焼成による $\mathrm{Cd}$ 揮発物質形態はこの場合塩化物形態と金属形 態が考えられる。それぞれの蒸気圧は熱力学データ(「非鉄金属製 錬」日本金属学会) より計算してFig.4 に示した。これらから金属 状カドミウムは蒸気圧が非常に高く, また Fig.7 に示すように $\mathrm{CdCl}_{2}$ 蒸気圧も $\mathrm{PbCl}_{2}$ と同等と高い。従って $\mathrm{Cd}$ 化合物は非常に揮 発しや寸く, いずれの化合物でも容易に揮発除去が可能である事 がわかる。一方塩化反応における標準自由エネルギーを $\mathrm{Cd}$ と $\mathrm{Pb}$ について比較すると, 式(1)(2)のようになり, 温度依存性を考慮 しても, $\mathrm{Pb}$ と比較して塩化反応は起こりにくいことがわかる $4,9,10,13,14)$ 。( 熱力学データは日本金属学会「非鉄金属製錬」)。

$$
\begin{aligned}
1 / 2 \mathrm{CdO}(\mathrm{s})+\mathrm{HCl}(\mathrm{g}) & =1 / 2 \mathrm{H}_{2} \mathrm{O}+1 / 2 \mathrm{CdCl}_{2} \\
\Delta \mathrm{G}^{\mathrm{O}}(\mathrm{J}) & =-70725+32.34 \times \mathrm{T} \\
\Delta \mathrm{G}^{\mathrm{o}} & =-32.8(\mathrm{~kJ}) \\
1 / 2 \mathrm{PbO}+\mathrm{HCl} & =1 / 2 \mathrm{PbCl}_{2}+1 / 2 \mathrm{H}_{2} \mathrm{O} \\
\Delta \mathrm{G}^{\mathrm{o}}(\mathrm{J}) & =-94,785+47.22 \times \mathrm{T} \\
\Delta \mathrm{G}_{1173}^{\mathrm{o}} & =-39.4(\mathrm{~kJ})
\end{aligned}
$$

このように $\mathrm{Cd}$ の塩化反応は $\mathrm{Pb}$ と比較して起こりにくく, 現実的 にも試験結果として $900^{\circ} \mathrm{C}$ 付近までは全く起こっていない。また $900 \sim 1000^{\circ} \mathrm{C}$ 付近の限られた温度領域でのみ $\mathrm{Cd}$ は $\mathrm{Pb}$ より優先的 に除去されており単純に塩化物揮発では説明しにくい。

次に金属状カドミウムの揮発に関して, 塩化反応と還元反応を 熱力学データ ( 熱力学データは日本金属学会「非鉄金属製鍊」) を もとに計算して比較検討した。

式 (1)(3)に各反応式及び熱力学データを示した。また Fig.5には 両反応の標準自由エネルギーの比較及び温度依存性を示した。こ れによれば $\mathrm{Cd}$ は温度の上昇とともに生成しやすい傾向にあり,か つ高温領域では塩化反応よりも還元反応のほうが起こりやすいこ とがわかる。

以上の知見および Cd の場合減少が高温度で始まっていること

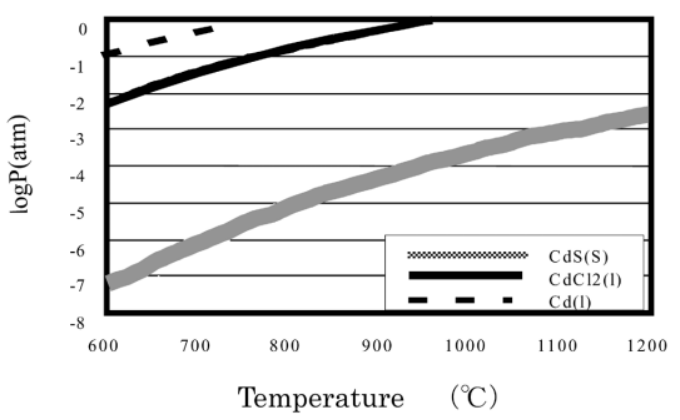

Fig. 4 Vapor pressure of each $\mathrm{Cd}$ compound.

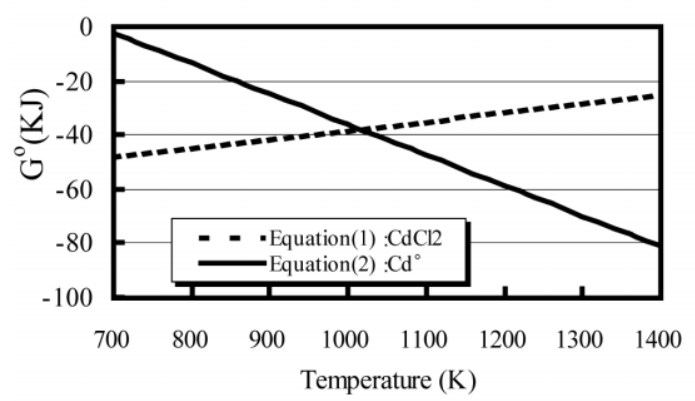

Fig. 5 Relation between $\Delta \mathrm{G}^{0}$ and temperature.

からも, 主に金属状 $\mathrm{Cd}$ として揮発していることがわかる。従来の 報告から, $\mathrm{Cd}$ と $\mathrm{Pb}$ は除去挙動が異なり揮発機構が異なることが 予想されたが, 以上のように高温度では $\mathrm{CdO}$ は還元されて金属状 となり，速やかに揮発分離していることがわかる。

$$
\begin{aligned}
& \mathrm{CdO}+\mathrm{CO}=\mathrm{Cd}+\mathrm{CO}_{2} \\
& \quad \Delta \mathrm{G}^{\mathrm{o}}(\mathrm{J})=76780-112.90 \times \mathrm{T}(\mathrm{K})
\end{aligned}
$$

次に反応促進に必要な $\mathrm{CO}$ 分圧を計算し, 試験条件との整合性 を確認する。還元反応の場合式 (3)より以下のように計算される。

$$
\begin{aligned}
\mathrm{K}_{3}= & \alpha_{\mathrm{Cd}^{\circ}} \times \mathrm{P}_{\mathrm{CO}_{2}} / \alpha_{\mathrm{CdO}} \times \mathrm{P}_{\mathrm{CO}} \\
\Delta \mathrm{G}^{\mathrm{o}} & { }_{1173 \mathrm{~K}}=-55.6 \mathrm{~kJ} \\
& \left(\alpha_{\mathrm{cd}^{\circ}} \text { : 金属 } \mathrm{Cd} \text { の活量, } \mathrm{P}_{\mathrm{co}_{2}}: \mathrm{CO}_{2} \text { ガスの分圧 }\right)
\end{aligned}
$$

これらより還元反応に必要な $\mathrm{P}_{\mathrm{co}_{2}} / \mathrm{P}_{\mathrm{co}}$ 比は比較的高く, $900{ }^{\circ} \mathrm{C}$ で約 1.0 であり, 実測值例の $0.31\left(1000^{\circ} \mathrm{C}\right)$ では $\mathrm{CdO}$ は充分還元されて 金属状になることがわかる。

以上より $\mathrm{CdO}$ の還元反応はキルン内の中温度領域から始まり, また高温度領域で活発に起こることがわかる。

実際 $\mathrm{Cd}$ の減少は主に $900^{\circ} \mathrm{C}$ から $1000^{\circ} \mathrm{C}$ の温度領域で発生して いることから ${ }^{4,6,8-10,13,14)}, \mathrm{Cd}$ の揮発除去は主に還元反応による金 属形態 $\left(\mathrm{Cd}^{\circ}\right)$ で起こっている事があらためて確認できる。

また溶出データ (Fig.6)から溶出に与える焼成温度の影響がうか がわれ, 温度が充分に高温であれば溶出量も容易に低レベルにと どめることが可能である事が推察される。

また Table 2 基礎調査結果には各成分の揮発除去難易性ととも に, 重金属溶出量も示したが, 溶出量は残留量とは対応関係が薄 く, 別の要素の影響を強く受けることが示唆される。

\section{$4 \cdot 2 \mathrm{Zn}$ の揮発除去機構について}

$4 \cdot 2 \cdot 1$ 飛灰処理における $\mathrm{Zn}$ の揮発解析 今回のキルン 実証試験では充分な還元条件を与えなかったこともあり, Zn 残留 濃度は概ね $0.7 \%$ 程度までの減少にとどまった。また $\mathrm{Zn}$ の減少は $900 \sim 950^{\circ} \mathrm{C}$ 付近から見られ, 塩素の減少挙動に類似することか ら, 揮発機構は還元揮発のほか塩化物揮発の可能性が考えられる。 


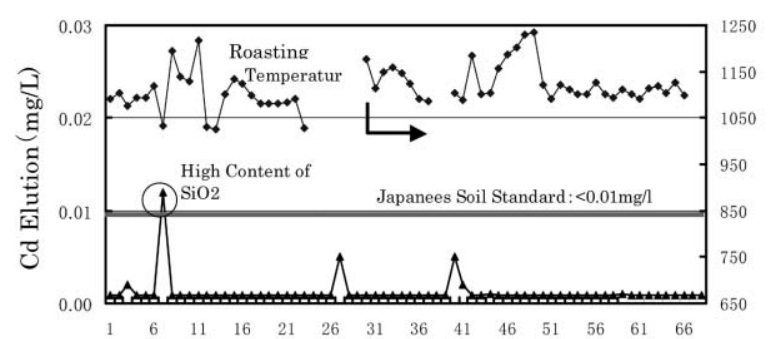

Run No.

Fig. 6 Cd elution results of roasted pellet.

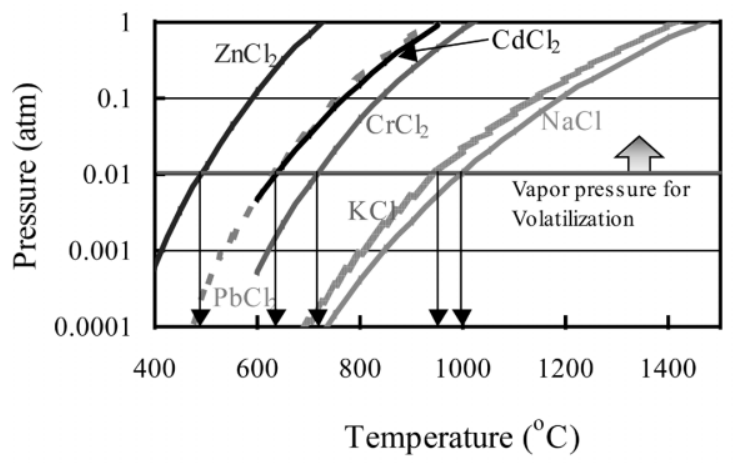

Fig. 7 Vapor pressure of various metal chlorides.

Fig.7 に各重金属塩化物の蒸気圧を比較して示した ( 熱力学デー 夕は日本金属学会「非鉄金属製錬」)。 $\mathrm{ZnCl}_{2}$ の蒸気圧は $\mathrm{PbCl}_{2}$ と 比較しても非常に高い事がわかる。これは $\mathrm{Zn}$ が塩化物になれば速 やかに揮発する事を示すものである。しかしながら式 (4) より以 下のように計算されるように,

$$
\begin{gathered}
\Delta \mathrm{G}_{1173}^{\mathrm{O}}=0.5(\mathrm{~kJ}) \\
\mathrm{K}_{4}=\alpha^{1 / 2}{ }_{\mathrm{ZnCl}_{2}}+\mathrm{P}^{1 / 2} \mathrm{H}_{2} \mathrm{O} / \alpha^{1 / 2} \mathrm{ZnO} \times \mathrm{P}_{\mathrm{HCl}}
\end{gathered}
$$

$\mathrm{Zn}$ の場合塩化物生成反応が比較的起こりにくく, かつ $900^{\circ} \mathrm{C}$ 以上 では反応そのものが起こりにくいことから ${ }^{4,6,8-10,13,14)}$, あえて塩 化物形態で揮発除去する場合は例えば $\mathrm{CaCl}_{2}$ などの塩化水素源を 添加して $\mathrm{P}_{\mathrm{HCl}}$ を高める必要がある ${ }^{11)}$

$$
\begin{aligned}
& 1 / 2 \mathrm{ZnO}+\mathrm{HCl}= 1 / 2 \mathrm{ZnCl}_{2}+1 / 2 \mathrm{H}_{2} \mathrm{O} \\
& \Delta \mathrm{G}^{\mathrm{O}}(\mathrm{J})=-54,450+46.89 \times \mathrm{T}
\end{aligned}
$$

( 熱力学データは日本金属学会「非鉄金属製錬」)

ここで $\mathrm{ZnCl}_{2}, \mathrm{ZnO}$ の活量を 1 と仮定し, ベッド層の水蒸気分圧 を可能性の高い領域の $10^{-3} \sim 10^{-6} \mathrm{~atm}$ と仮定すると, ベッド層に おける式 (4) の平衡 $\mathrm{HCl}$ 分圧は概称 $10^{-1.5} \sim 10^{-3} \mathrm{~atm}$ と比較的高 い值が必要となり, 外部から塩化水素源を添加しない限り塩化反 応は起こりにくいことがわかる。なおキルンベッド層中の水蒸気 分圧は，精度ある実測が難しいため, $\mathrm{ZnCl}_{2}$ 生成の $\mathrm{HCl}$ 平衡分圧は 確定できないが, $\mathrm{ZnCl}_{2}$ 生成が確認されないことから, ベッド層中 水蒸気分圧は少なくとも $10^{-6} \mathrm{~atm}(\mathrm{HCl}$ 生成平衡水蒸気分圧) 以上, かつ実測下限值 $\left(10^{-3} \mathrm{~atm}\right.$ 未満 $)$ の間にあると推定される。

また Table 4 に示したキルン内 $\mathrm{P}_{\mathrm{HCl}}$ 実測值を岩沢ら ${ }^{5)}$ 山口ら ${ }^{7)}$ の酸化物 / 塩化物平衡図 (Fig.8) に図示した。なお図中プロットは $\mathrm{P}_{\mathrm{H}_{2} \mathrm{O}}=10^{-4} \mathrm{~atm}$ と仮定して計算した。これは酸素の場合, ベッド層 中分圧 (約 $0.0 \mathrm{n} \%)$ がガス層分圧 $(2 \%)$ のほぼ $10^{-2}$ 倍となること を参考例とし, 更に $\mathrm{ZnCl}_{2}$ 生成側条件として一桁低い值を想定し た $\left(\mathrm{P}_{\mathrm{H}_{2} \mathrm{O}}=10^{-4} \mathrm{~atm}\right)$ ものである。

これらの結果より, $\mathrm{HCl}$ 分圧が比較的高いベッド層内でも $\mathrm{ZnCl}_{2}$ の生成は塩化材添加無しには難しいことがわかり, また $\mathrm{Pb}$ の場合 は塩化材添加無しでもベッド層で充分 $\mathrm{PbCl}_{2}$ が生成することがわ

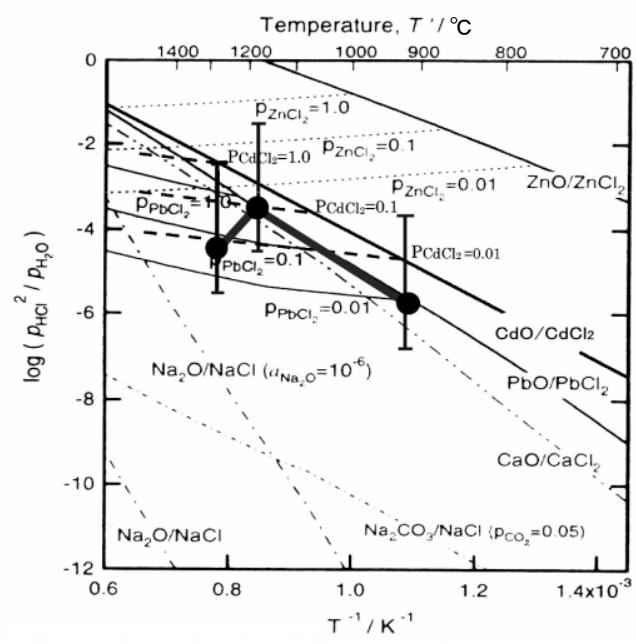

Fig. 8 Mesured $\mathrm{P}_{\mathrm{HCl}}$ (Bed Layer) and Chloride-Oxide Diagram of $\mathrm{Pb}, \mathrm{Zn}$.

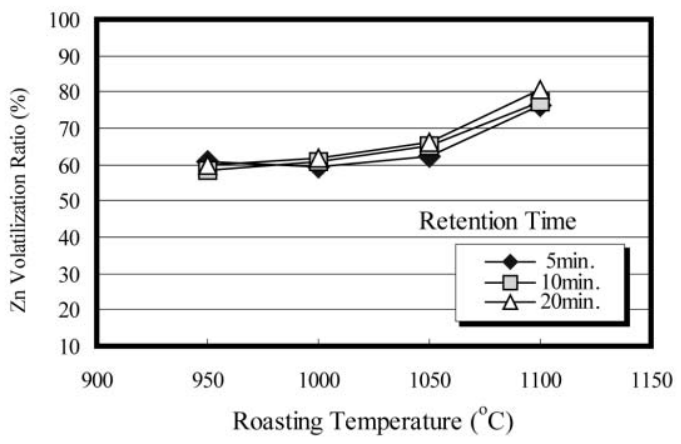

Fig. 9 Influence of roasting temperature and retention time according to $\mathrm{Zn}$ vaporization (Basic test).

Table 5 Changes of $\mathrm{Zn}$ volatilization ratio (\%) according to roasting temperature (Basic test)

\begin{tabular}{c|c}
\hline $\begin{array}{c}\text { Roasing temp. } \\
\left({ }^{\circ} \mathrm{C}\right)\end{array}$ & $\begin{array}{c}\text { Zn voratilization } \\
\text { ratio(\%) }\end{array}$ \\
\hline \multirow{2}{*}{950} & 82.3 \\
\cline { 2 - 2 } & 84.3 \\
\hline \multirow{2}{*}{1000} & 98.7 \\
\cline { 2 - 2 } 1050 & 98.6 \\
\cline { 2 - 2 } 105 & 99.2 \\
\hline \multirow{2}{*}{1100} & 99.4 \\
\cline { 2 - 2 } & 99.8 \\
\hline
\end{tabular}

Reduction atmosphere

Coke increase-in-quantity addition Roasting time is $60 \mathrm{~min}$.

かる。

Fig.9 には Zn 揮発に及ぼす焼成温度の影響と滞留時間の影響に 関する基礎試験の結果を示した。これら基礎試験は飛灰ペレット を定置式加熱装置に静置し, 特に還元性強化はせず通常の $\mathrm{N}_{2}$ ガ ス雰囲気 (11/分) で行った。Fig.9 に示した基礎試験結果では滞留 時間の影響は不明確だが, 温度の影響は比較的明確に得られ, $1100{ }^{\circ} \mathrm{C}$ では約 $75 \sim 80 \%$ の揮発率を示した。適切な条件を満たす ことにより飛灰中Znについてもある程度高い揮発率が期待できる ことがわかる。更に C 量を高め ( 含有量約 $8 \%$ ), 同時に温度を変化 させた還元揮発試験を行ったところ, 非常に高い揮発率が得られ た (Table 5)。これらは還元雾囲気が与えられた結果, 還元揮発反 応が $950^{\circ} \mathrm{C}$ 付近では充分起こっていたことを示すものである。ま た更に塩化物揮発性の確認のため塩化水素源として $\mathrm{CaCl}_{2}$ の添加 試験を $1050^{\circ} \mathrm{C}$ で行いその結果を Table 6 に示した。これら $\mathrm{CaCl}_{2}$ 添加試験において高い $\mathrm{Zn}$ 回収率が得られたことから, 飛灰処理に おける塩化反応による $\mathrm{Zn}$ 揮発除去は, 一定温度領域における塩化 
Table 6 Changes of $\mathrm{Zn}$ volatilization ratio(\%) by $\mathrm{CaCl}_{2}$ addition (Basic test)

\begin{tabular}{c|c}
\hline $\begin{array}{c}\mathrm{CaCl}_{2} \\
\text { additional }\end{array}$ & $\begin{array}{c}\mathrm{Zn} \text { voratilization } \\
\text { ratio(\%) }\end{array}$ \\
\hline \multirow{2}{*}{5} & 99.4 \\
\cline { 2 - 2 } 10 & 99.2 \\
\cline { 2 - 2 } 20 & 99.6 \\
\cline { 2 - 2 } 20 & 99.1 \\
\hline \multirow{2}{*}{ Roasting temperature : 1050} \\
Atmophere : Nitrogen gas \\
(flow rate : $1 \mathrm{~L} / \mathrm{C}$ min.)
\end{tabular}

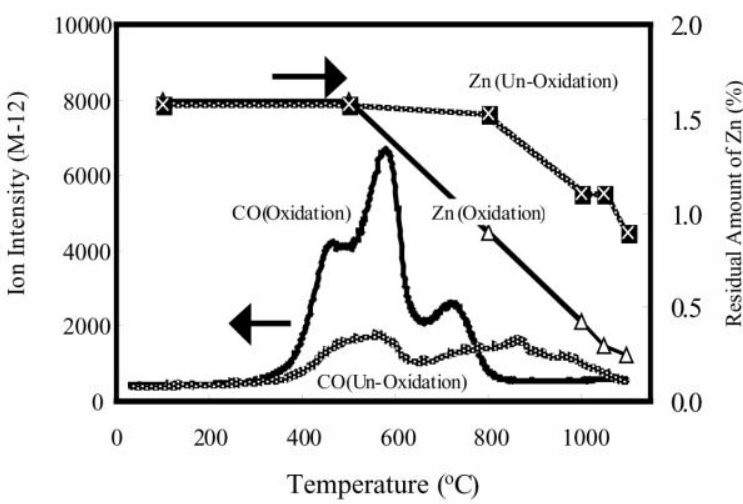

Fig. 10 Relation between CO gas generation and Zn decreasing.

水素ガス分圧の向上によっても，実際面において期待できること がわかる。

$4 \cdot 2 \cdot 2 \mathrm{Zn}$ 含有飛灰からの $\mathrm{Zn}$ 回収における還元揮発技術適 用の可能性溶融飛灰など $\mathrm{Zn}$ 含有量が高い材料の場合は, 有害 成分の除去と同時に Zn の回収が主要な目的になり, 還元性強化及 び処理温度上昇による金属亜鉛としての揮発回収も有効な方法で ある。このため熔融炉飛灰類の還元揮発の可能性についても検討 した。

飛灰類の場合, その組成の特徵から溶融温度が比較的低い化合 物を多く含有しており，ペレットの融着問題を回避しつつ ZnO を 還元し, 充分揮発分離することが重要となる。Fig.10に飛灰ペレッ 卜を使用した CO ガスの発生及びZnの揮発減少状況を調查した基 礎試験結果を示した。測定雰囲気については, ベッド層表面 ( 酸 化雰囲気) およびペレット内部を想定した (非酸化雰囲気) 両反応 を再現することを目的として, 酸素 $3 \%$ 含有へリウムガス気流中 ( 酸化雾囲気想定)，および $100 \%$ ヘリウムガス気流中 ( 非酸化雾 囲気想定 ) とした。C は約 5\%, また昇温速度はキルン炉に投入直 後の比較的急激な昇温とキルン炉内での緩やかな昇温を模して, $600^{\circ} \mathrm{C}$ を分岐点として昇温速度を変えて測定した。

この結果から CO ガスの発生は比較的低温度で発生し, 更に酸 素の存在で促進され, また同時に Zn の減少が起こっていることが 確認された。従って比較的低温度における $\mathrm{Zn}$ の還元揮発はこの場 合可能であることがわかる。また Zn 揮発率に及ぼす還元雾囲気及 び焼成温度は重要であり，基礎試験からは C は $5 \%$ 程度以上，焼 成温度は $1000^{\circ} \mathrm{C}$ 程度以上が好ましい条件であることがわかった。 これら Znの還元揮発状況を大型キルン実証試験設備において試験 した結果が Fig.11 である。試験条件は装入量 $100 \mathrm{~kg} / \mathrm{h}$ 焼成温度 $1100^{\circ} \mathrm{C}$ である。キルン装入口から $8 \mathrm{~m}$ 付近はキルン内部温度は約 $900^{\circ} \mathrm{C}$ であり，この部分で急激に $\mathrm{Zn}$ 揮発率が上昇し，同時に残留 $\mathrm{C}$ が急減しており，Zn が還元されて揮発している様子が現れてい る。この結果から適切な還元条件を与えれば比較的操業温度の低 い本キルン焼成法でも, 飛灰中 $\mathrm{Zn}$ の還元揮発除去は実用的にも充

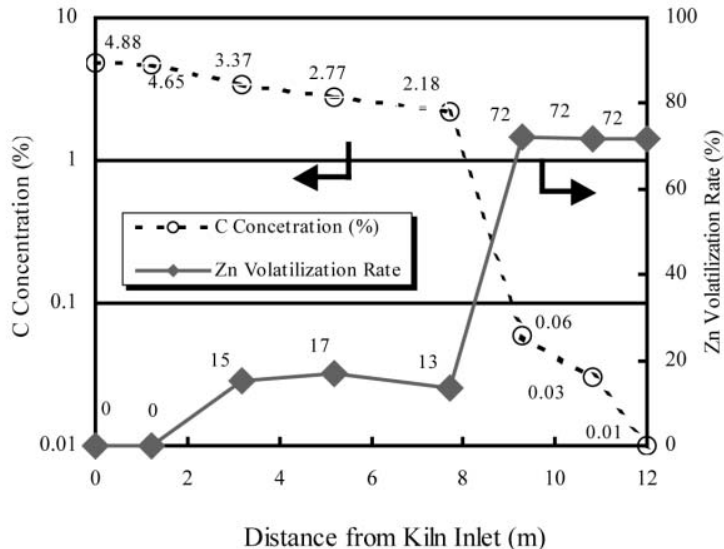

Fig. 11 Transition of $\mathrm{Zn}$ vaporization and residual $\mathrm{C}$.

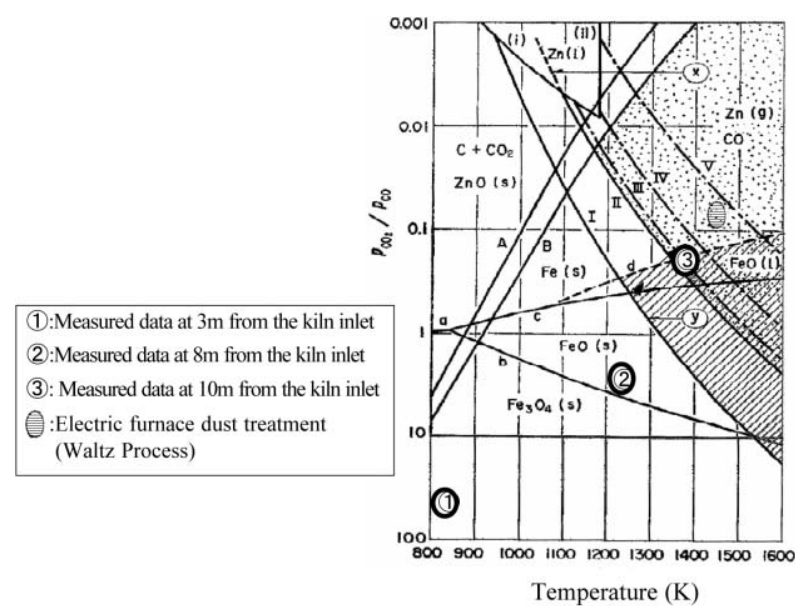

Fig. 12 Transition of the mesured atmosphere $\mathrm{P}_{\mathrm{CO}_{2}} / \mathrm{P}_{\mathrm{CO}}$ in the kiln bed layer.

分可能であることがわかる。

Fig.12 はブルドワ平衡図 ${ }^{16)}$ に, 飛灰を使用した大型キルン実証 試験におけるガス分析值をプロットしたものであり，原料飛灰ぺ レットが焼成キルンの入り口から出口に至るまでのベッド層内還 元度の推移をあらわしている。EAFD : (Electric Arc Furnace Dust) 処理における Waelz キルンの主要還元領域の条件例も同時に 1 点 示した。

EAFD 処理法である Waelz キルンは高温還元法による Zn の揮発 回収を目的としており,かつ Fig.12 から判断されるように還元条 件は本飛灰処理法条件と類似しており ${ }^{15,16)}$ 焼却飛灰類の $\mathrm{Zn}$ 揮発 除去に関し有効かつ具体的な参考になるものである。

Fig.12によると本飛灰処理試験条件でも, 還元条件は高温領域 において, $\mathrm{FeO}$ 安定領域から $\mathrm{Fe}^{\circ}$ 安定領域まで強まっている事が わかる。従って焼却炉飛圧の Zn の残留量減少に関しては, Waelz キルンと同様に，適量の還元剤の追加及び融着防止技術により， $\mathrm{ZnO}$ の還元揮発が充分有効であることが改めて推察される。

$4 \cdot 3 \mathrm{Cr}$ の揮発除去性および安定化について

$4 \cdot 3 \cdot 1 \mathrm{Cr}$ の揮発性について $\mathrm{Cr}$ 関しては塩化物など形 態により高い蒸気圧を示寸ものもあるが，本試験条件における揮 発除去率は極めて低く, 揮発分離は難しいと思われる。

$$
\begin{gathered}
2 / 3 \mathrm{Cr}_{2} \mathrm{O}_{3}(\mathrm{~s})+4 \mathrm{HCl}(\mathrm{g})=4 / 3 \mathrm{CrCl}_{3}(\mathrm{~s})+2 \mathrm{H}_{2} \mathrm{O} \\
\Delta \mathrm{G}^{\mathrm{o}}(\mathrm{J})=-102,920+255.10 \mathrm{~T} \\
\Delta \mathrm{G}^{\mathrm{o}}{ }_{1173}=196(\mathrm{~kJ})
\end{gathered}
$$




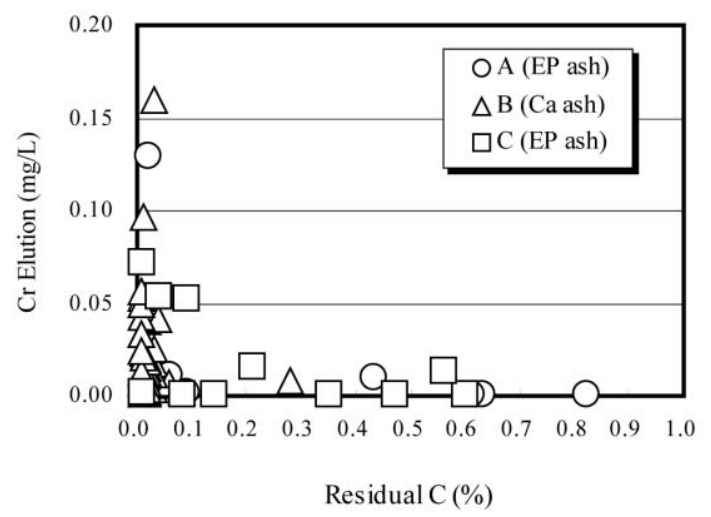

Fig. 13 Relation between residual $\mathrm{C}$ content and Cr elution.

( 熱力学データは日本金属学会「非鉄金属製鍊」) 式 (5) より本焼成温度条件では塩化反応が起こりにくいことは明 らかである。従って Cr の塩化物揮発は本飛扊類の処理条件では難 しく, むしろ溶解性の低い形態に安定させる方法が有効と思われ る。乾式処理の場合酸化䨌囲気にさらすと, Cr は比較的容易に 6 価になり, 従って処理工程では適切な還元雾囲気を維持した条件 下で焼成することによってCrを 3 価に維持しつつ固定化させるこ とが重要である。Fig.13に焼成ペレット中残留炭素濃度と Cr 溶出 量の関係を示した。EAFD から Zn を回収する Waelz 技術の場合, 残留 $\mathrm{C}$ が $0.2 \%$ 程度あれば $\mathrm{Cr}$ の溶出量は $0.01 \mathrm{mg} / \mathrm{l}$ 以下になること が現場操業経験として知られているが, Fig.13より Waelz 技術と 同様, 本飛扊焼成技術でも $\mathrm{Cr}$ の溶出を防ぐ操業条件が比較的容易 に得られることがわかる。

実証試験において得られた焼成ペレットの Cr 溶出量は, 酸化条 件試験を除けば,いずれの試験条件のものも全て $<0.01 \mathrm{mg} / l$ であっ た。また Table 7 には公共機関による溶出試験結果を示したが, い ずれも検出下限以下であった。これらより Cr は本技術により強固 に安定化していることがわかる。

\section{5. まと め}

以上キルン焼成法による飛灰類の重金属の挙動に関し検討を加 えた結果, $\mathrm{Pb}$ は主に塩化物, $\mathrm{Zn}$ 及び $\mathrm{Cd}$ は主に金属形態で揮発除 去される事があらためて確認された。また Cr に関しては通常の操 業条件では塩化反応が起こりにくく, 塩化物揮発除去は難しいこ
Table 7 Result of the Cr Elution (mg/l).

\begin{tabular}{l|l|l}
\hline $\begin{array}{l}\text { Elution result by } \\
\text { notification No.46 } \\
\text { of Japan }\end{array}$ & $\begin{array}{l}\text { Elution } \\
\text { result } \\
\text { at pH4 }\end{array}$ & $\begin{array}{l}\text { Japanese soil } \\
\text { environmental } \\
\text { standard }\end{array}$ \\
\hline$<0.01$ & $<0.01$ & $<0.05$ \\
\hline
\end{tabular}

とがわかった。従って Crに関しては溶出性を抑えることが肝要で あり, やや還元性雾囲気を維持することにより酸化を防止し，ま た処理温度を極力高めに設定することで比較的容易に安定化でき ることがわかった。

謝辞本研究を推進するに当り, 新エネルギー・技術開発機 構, 資源環境センター等のご協力を頂きました。ここに感謝いた します。

\section{References}

1) J.Takahashi, K.Toyabe, Y.Sakamoto and M.Matsuno : Proceedings MMIJ Autumn Meeting, (1997), CV-7, p.113.

2) J.Takahashi, K.Tomoda and M.Matsuno : Proc.MMIJ Fall Meeting, (2000), D3-2, pp.49-52.

3) K. Tomoda et. al.: Waste Processing and Recycling in Mineral and Metallurgical Industries IV, $40^{\text {th }}$ Annual Conference of Metallurgist of CIM, (Toronto, Canada, 2001), pp.125-136.

4) J.Takahashi, K.Tomoda and M.Matsuno : Proc.MMIJ Fall Meeting, (2001), D4-2, pp.229-232.

5) K.Iwasawa, S.Yamaguti, T.Okabe and M.Maeda : Proc.MMIJ Fall Meeting, (2001), D54, pp.261-263.

6) J.Takahashi, K.Tomoda and M.Matsuno : Proc. TMS Fall Meeting, (2002), vol.2, pp. $473-480$.

7) S.Yamaguchi, K.Iwasawa, and M,Maeda : Proc. TMS Fall Meeting, (2002), vol.2, pp.457-462.

8) K.Tomoda and M.Matsuno : Proceedings of the 13th Study Lecture Congress, (2002), B8-3, pp.507-509, Japan Society of Waste Management Experts (JSWME).

9) M.Matsuno and K.Tomoda : Proc. TMS 132 Annual Meeting \& Exhibition Yazawa International Symposium, (2003), Vol.1, pp.1093-1101.

10) M.Matsuno, K.Tomoda and J.Takahashi : Proc.MMIJ Fall Meeting, (2003), Vol. II , pp.226-227.

11) K.Onishi: First Symposium of molten fly ash recycling, Waseda University,(2003), "Field test for molten fly ash recycling, Speech summary".

12) K.Kawamoto, K.Tomoda and M.Matsuno : Proceedings of the 15th Study Lecture Congress, (2003), B-8-8, Japan Society of Waste Management Experts (JSWME).

13) M.Matsuno, K.Tomoda, K.Kawamoto and T.Nakamura : JSWME, Impressed.

14) M.Matsuno, K.Tomoda and T.Nakamura : Materials Transactions, 12(2003), Vol.44, 2481-2488.

15) T.Azagami, A.Yazawa : (SENKEN IHO) Bullction of the Reseach Institute of Mineral Dressing and Metallurgy Tohoku University, Vol.21, (1965), No.1, pp.103-112.

16) K.AZA and S.Ito : Proc.MMIJ Annual Meeting, (1989), D1, pp.47-50.

17) K.Hayashi, Y.Kubota, K.Tomoda and M.Matsuno : Proceedings of the 53 th Congress of Mine and Smelting Practical Engineers, Analysis section, (2003), pp.17-20. 